\title{
Incorporating public transport in a methodology for assessing resilience in urban mobility
}

DOI:

10.1016/j.trd.2020.102386

\section{Document Version}

Accepted author manuscript

Link to publication record in Manchester Research Explorer

\section{Citation for published version (APA):}

Gagno Azolin, L., Rodrigues da Silva, A. N., \& Pinto, N. (2020). Incorporating public transport in a methodology for assessing resilience in urban mobility. Transportation Research. Part D: Transport \& Environment: an international journal , 85, [102386]. https://doi.org/10.1016/j.trd.2020.102386

\section{Published in:}

Transportation Research. Part D: Transport \& Environment: an international journal

\section{Citing this paper}

Please note that where the full-text provided on Manchester Research Explorer is the Author Accepted Manuscript or Proof version this may differ from the final Published version. If citing, it is advised that you check and use the publisher's definitive version.

\section{General rights}

Copyright and moral rights for the publications made accessible in the Research Explorer are retained by the authors and/or other copyright owners and it is a condition of accessing publications that users recognise and abide by the legal requirements associated with these rights.

\section{Takedown policy}

If you believe that this document breaches copyright please refer to the University of Manchester's Takedown Procedures [http://man.ac.uk/04Y6Bo] or contact uml.scholarlycommunications@manchester.ac.uk providing relevant details, so we can investigate your claim.

\section{OPEN ACCESS}




\section{Incorporating public transport in a methodology}

\section{Abstract}

\section{Luiza Gagno Azolin}

Department of Transportation Engineering, São Carlos School of Engineering, University of São Paulo Av Trabalhador Sãocarlense, 400, São Carlos SP, Brazil

Telephone: +551633739595

E-mail: luiza.azolin@usp.br

\section{Antônio Nélson Rodrigues da Silva (corresponding author)}

Department of Transportation Engineering, São Carlos School of Engineering, University of São

\section{Paulo}

Av Trabalhador Sãocarlense, 400, São Carlos SP, Brazil

Telephone: +551633739595

E-mail: anelson@sc.usp.br

Spatial Policy and Analysis Lab, Manchester Urban Institute, The University of Manchester Oxford Rd, Manchester M13 9PL, United Kingdom

Telephone: +441612752729

E-mail: nuno.pinto@manchester.ac.uk

\section{Incorporating public transport in a methodology} for assessing resilience in urban mobility

Resilience has gained importance in the current research and policy agendas as it incorporates concepts of adaptation and transformation. Urban areas are complex systems exposed to different shocks, which have impacts on its various components. Research in transport has already incorporated the concept of resilience with more or less sophisticated approaches that are intensive on data and technical expertise. There is a need to explore the incorporation of resilience in simpler and less data 
intensive methods that can be easily applied in a wider range of contexts. One of the aims of this research is to develop a method that can use commonly available mobility management tools allowing smaller urban areas to analyse and plan for resilience. We present a new development of a method to assess resilience in transport systems with a commonly used mobility management tool (the origindestination matrix) for calculating an overall measurement of resilience. The method assumes that car trips are transferred to active modes or to the available public transport routes in the event of any disruption in the system. We consider different scenarios of availability of public transport in case of disruptive events. We applied the method to two urban areas in Brazil. The variation of the contribution of the public transport presents patterns comparable between the two cases. The spatial distribution of trips shows the relative importance of resilient trips and the cities' spatial structure. The inclusion of public transport routes has an impact on the levels of accessibility of lower income users.

Keywords: resilience, urban mobility, public transport, active modes, Brazil

\section{Introduction}

This paper presents the results of the application of a method to classify the level of resilience of urban trips in the event of total unavailability of cars and with potentially restricted use of public transport. The main goal of the research is to develop a robust analytical tool for resilience applicable in low intensity data contexts (i.e., contexts without comprehensive and/or detailed datasets), which allows less capacitated management bodies to plan and respond to disruptive events due to climate change or socioeconomic unrest.

Urban development based on heavy transport infrastructure development contributed to a society increasingly more dependent on a car-based mobility (Wiersma et al., 2017) and, as a consequence, cities more vulnerable to various risks that impact the use of the car and other (internal combustion) motorised vehicles. At the same time, we are living the rise of the state of climate emergency (Let's work together, 2020), with multiple nations and international organisations as the United Nations (UN) and the European Union pushing for strong measures for greenhouse gases emissions reduction, in a context where severe disruptions due to climate change are occurring with more severity and higher frequencies. Social and economic uncertainties also affect mobility. The UN Sustainable Development Goals framework and agenda aims at creating more inclusive territories and cities for sustainable urban development and growth (United Nations, 2015). Sustainable urban development 
60 frameworks generally includes more efficient transport systems and reduced dependency from private 61 car mobility (Zhao, 2010).

62 The concept of resilience was introduced to environment studies in the early 1970s as the capacity of 63 a system to maintain its functions absorbing changes caused by possible disruptions (Holling, 1973). 64 It has been later detailed and its components identified. It includes the capacity of a system to: (1) resist (Berche et al., 2009; D’Lima and Medda, 2015; Jin et al., 2014); (2) adapt itself (Bruneau et al., 2003; Chan and Schofer, 2016; Ta et al., 2009); and (3) transform itself (Berdica, 2002; Mattsson and Jenelius, 2015; Seeliger and Turok, 2013) in order to recover from a shock, absorb its consequences and maintain levels of functionality. Transport systems are in the forefront of the impacts of all types of shocks, from environmental to social and economical changes. Cox et al. (2011) assessed the effects of the July 2005 terrorist attacks on the metro and bus systems in London. Chan and Schofer (2016) studied the consequences suffered by the rail transport service of the New York City after severe climate change events (hurricanes and blizzard). Moreover, Brazil has recently suffered some events of severe disruption due to fuel price peaks and lack of proper policy control (Lopes Da Silva et al., 2019). Analysing the resilience levels of transport systems is therefore key to better strategic and operational planning and risk management (D'Lima and Medda, 2015). Transport policies targeting the development of better infrastructure and better operational performance can increase urban resilience in the long term (Leung et al., 2017). The consideration of active transport modes also contributes to the increase of resilience levels as these modes have no or lower dependencies on fuel (Fernandes et al., 2019) and more functional infrastructure. The literature on resilience in transport has still few examples of analysing resilience considering active modes and mode transfer (Berche et al., 2009; D'Lima and Medda, 2015; Jin et al., 2014; Martins et al., 2019).The literature has very few approaches based on simple mobility indicators that could be applied in contexts of data scarcity and lack of advanced expertise. This paper presents a new iteration of a research project on the development of a methodology for assessing the overall resilience of transport systems in the event of severe disruptions due to natural and socio-political events, with its first iteration reported in Martins et al. (2019). Our study aims at developing further the methodology by incorporating the public transport mode in the calculation of the index of urban mobility resilience. Public transport is a key mode that should be considered in disruptive events due to its social function in providing accessibility to all. This can potentially help decision makers to manage the transportation systems in both its strategic and operational layers. The study also analyses the relationship between resilient trips and income. Section 2 presents a literature overview introducing the concepts of resilience and how public transport has been considered. 
methodology to two cases studies in Brazil, the city of São Carlos, SP, and the Metropolitan Region of Maceió, AL. Finally, conclusions about the application and validity of the methodology are drawn on section 5 .

\section{A Brief Literature Overview}

Resilience can be defined as the capacity of ecosystems to return to their initial states when subjected to perturbations (Holling, 1973). The concept was latter explored and detailed considering its multiple components, namely function, structure, identity and, very important, existing feedbacks (Walker et al., 2004). Distinctions were also made between resilience as the return to a general equilibrium state in engineering or to possible multiple equilibrium states in ecology (Holling, 1996; Reggiani et al., 2015). Walker and colleagues also introduced the concepts of adaptability and transformability to consider the capacity of a system to exist in multiple states of stability (Walker et al., 2004). Adaptability can be defined as the capacity of the system to develop within the boundaries of its own stability (Folke et al., 2010). Transformability encompasses the possibility of a system to create or achieve new domains of stability (Fernandes et al., 2017). The inclusion of the concept of resilience is considered to be an improvement on risk analysis, as it incorporates holistic concepts of complexity, interdependency and uncertainty to characterise systems and their responses to exogenous shocks (Linkov et al., 2014). Many studies conducted by governments and NGOs have incorporated resilience based on these concepts (Coaffee et al., 2018).

Resilience is being incorporated in multiple frameworks of urban analysis (Ribeiro and Pena Jardim Gonçalves, 2019). The analysis of resilience in the transport system has been made through both qualitative and quantitative approaches, usually focusing on a single transport mode and the majority of times focusing on the operational aspects of the system (Leobons et al., 2019). Disruptive events are central to many of these analyses, addressing network disruption (D'Lima and Medda, 2015; Hong et al., 2019; Jin et al., 2014), economic or energy crisis (Fernandes et al., 2019; Santos et al., 2020), man induced disasters (Cox et al., 2011) and natural disasters (Chan and Schofer, 2016; Donovan and Work, 2017; Duy et al., 2019).

The impact of resilience in transport choice and transfer is also addressed, with research done on a single mode (Chan and Schofer, 2016; D'Lima and Medda, 2015), on mode demand compensation (Cox et al., 2011; Jin et al., 2014) or in assessing overall transfer mode from combustion engine based modes to active modes (Martins et al., 2019).

Energy crisis is a recurrent subject in analysing resilience in transport. Krumdieck et al. (2010) proposed a classification of trips considering their impact and the need to ensure a given standard of 
wellbeing. Trips have been classified as optional, the ones that could be eliminated without a significant reduction of wellbeing; necessary, which lead to important loss of accessibility but could nonetheless be eliminated; and essential, which correspond to basic accessibility needs (to jobs, health services, etc.). Krumdieck et al. (2010) classified the levels of impact as low, medium, high and very high. Leung et al. (2017) analysed the cases of Brisbane, Australia, and Hong Kong, China, highlighting the need to make accessible transport available to ensure transport resilience. Mattioli et al. (2019) analysed the vulnerability of English regions considering fuel cost increases. Fernandes et al. (2019) did a similar analysis where the impact of the cost increase on both public and private transport modes is assessed; however, it lacks a demand analysis considering origins and destinations. It is now abundantly clear that current environment and social uncertainties generate pressures on cities to deal with disruptions and many cities and towns (particularly the smaller ones) have a deficit of knowledge and evidence on how to address it. The use of common and validated urban and transport management tools, such as the origin-destination (OD) matrix, is key to ensure that these less capacitated entities can address these issues as well as more developed urban areas do.

\section{Methodology}

Our methodology is an extension of the method for assessing resilience in mobility presented in Martins et al. (2019). The method explores the distances that can be travelled in walking and bicycle modes in the event of unavailability of motorised modes. In this new approach, we evaluated what trips would or would not be affected if public transport is partially available. The method uses public transport itineraries and data of origin-destination (OD) surveys to build scenarios for identifying how different transit supply levels affect the resilience of mobility.

\subsection{Distances between TAZ centroids}

As this work proposes to establish a methodology with wide application, which uses commonly available data (OD surveys), we assumed the design simplification of considering the commonly used Traffic Analysis Zones (TAZ) and their centroids. As any methodology based on the use of TAZ, ours is constrained by this representation of the transport system. The first step of the method is the calculation of network distances between all centroids of TAZ. This results in a symmetric matrix with $n$ rows and $n$ columns, in which $n$ is the number of zones. All matrix entries are distance values greater than zero except the main diagonal. As proposed by Martins et al. (2019), the intrazonal trips are set to zero because they are supposed to be short trips, likely to be done by non-motorized modes. 


\subsection{Maximum Possible Distances (MPD) and scenarios of active modes}

157 As active modes distances are limited by characteristics of the individuals and also of the locations, 158 we assumed the concept of Maximum Possible Distances (MPD) for walking and cycling. These 159 essentially reflect the maximum distances an individual accepts to travel using these modes. The idea 160 is to define acceptable incremental values for MPD for walking and cycling and evaluate changes in 161 mode selection for different combinations of walking and cycling MPD, as used by Martins et al. 162 (2019). These combinations are used to build the scenarios for the analysis of resilience, with a single 163 restriction: MPD values for walking are always shorter than MPD for cycling. We adopted the same 164 procedures to build the scenarios of active modes, which were subsequently combined with different 165 scenarios of transit supply.

\section{$166 \quad 3.3$ Potential demand and scenarios of public transport}

167 The analysis of public transport involves the identification of the available transit modes in the study 168 area, number of routes per mode, routes characteristics (e.g., radial, circular, etc.), and TAZ crossed 169 by each route. The proposed procedures, which in large regions can be expedited if the datasets are 170 available as GIS files, are explained through a simplified example with five TAZ and one bus route 171 in Figure 1. As the outbound and inbound itineraries of route 1 are not coincident, the TAZ served in 172 each direction are different (Figure 1 and Table 1).

173

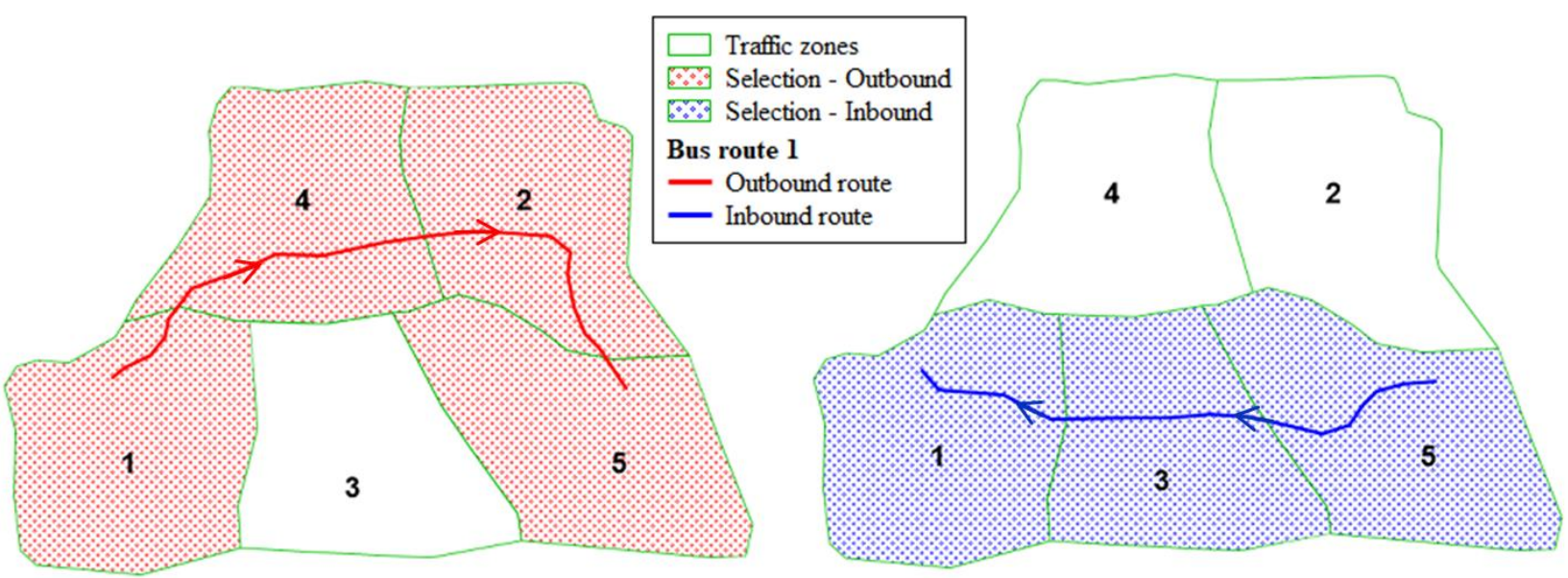

Figure 1 Identification of TAZ served by a bus route on outbound (red) and inbound (blue) directions on a hypothetical example

This example is further developed with two additional routes, as shown in Table 1. The zones served by each route are subsequently combined in a single matrix (i.e., the Matrix of Served Connections MSC), as shown in Table 2. The connections between zones are represented with a binary coding, in which one means that the pair of zones is connected by that route and zero otherwise. In the example, 
180

181

182

183

184

185

186

187

188

189

190

191

192

193

194

195

196

the differences between outbound and inbound directions are colour-coded in blue and red, respectively. In addition, intrazonal trips are not relevant in this process because we assume that they are short trips done by active modes. In a critical situation of fuel shortage, transit operators and managers are supposed to keep operating only priority routes. We propose to identify these routes by looking at the potential transit demand (PTD) of the transit routes, which can be obtained with a combination of OD data and the MSC.

Table 1 Identifying TAZ served by more than one bus route

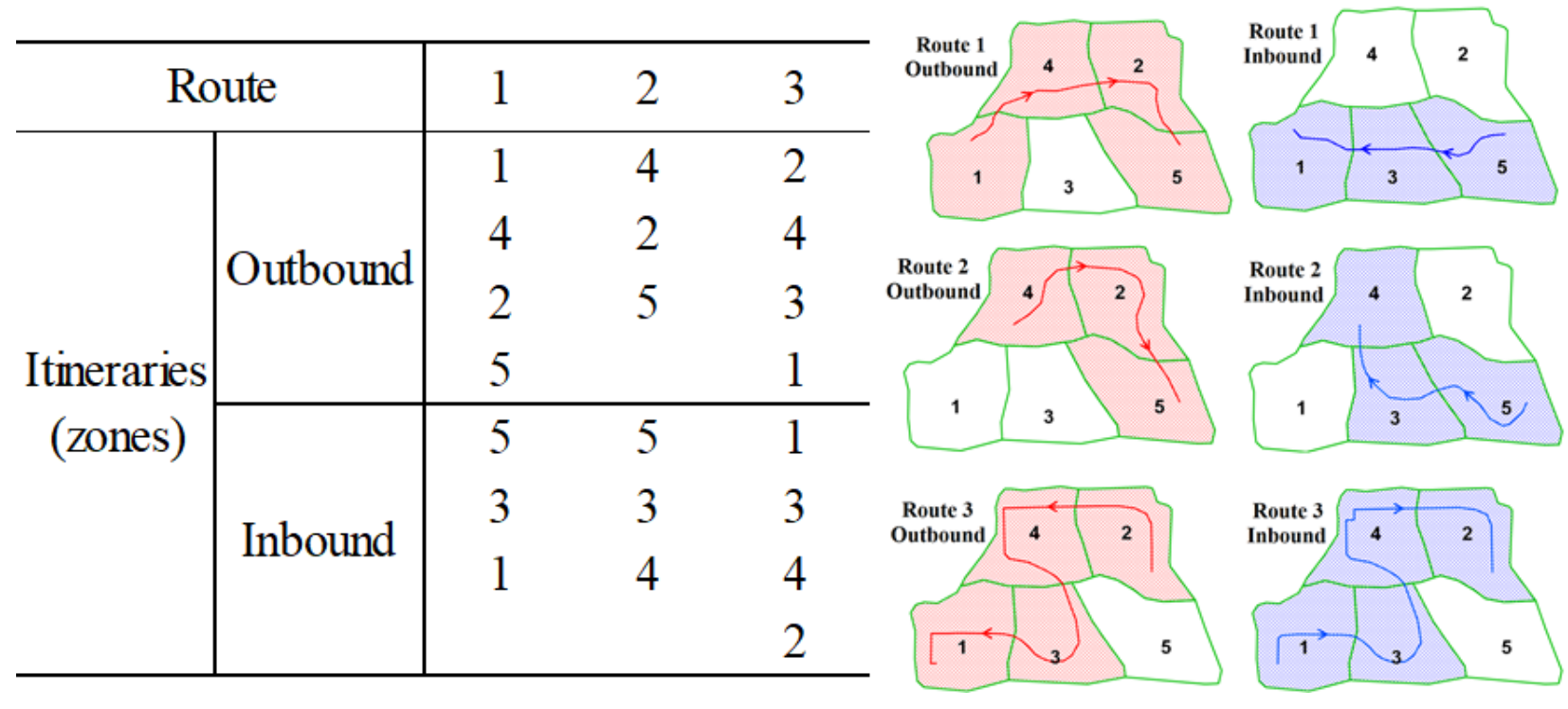

Table 2 Identification of routes serving each OD pair in the example of Table 1 (coding: 1 - connection served by transit; 0 - connection not served by transit; red - outbound connection; blue - inbound connection)

\begin{tabular}{c|ccccc}
\hline $\mathrm{O} \ \mathrm{D}$ & 1 & 2 & 3 & 4 & 5 \\
\hline 1 & - & $1 / 0 / 1$ & $0 / 0 / 1$ & $1 / 0 / 1$ & $1 / 0 / 0$ \\
2 & $0 / 0 / 1$ & - & $0 / 0 / 1$ & $0 / 0 / 1$ & $1 / 1 / 0$ \\
3 & $1 / 0 / 1$ & $0 / 0 / 1$ & - & $0 / 1 / 1$ & $0 / 0 / 0$ \\
4 & $0 / 0 / 1$ & $1 / 1 / 1$ & $0 / 0 / 1$ & - & $1 / 1 / 0$ \\
5 & $1 / 0 / 0$ & $0 / 0 / 0$ & $1 / 1 / 0$ & $0 / 1 / 0$ & - \\
\hline
\end{tabular}

93 The analysis of the PTD has to start with the identification of the available public transport modes 94 because some of them may not be affected by the constraints considered. For example, if the crisis is 95 related to the supply of fossil fuel, public transport modes operated by electric vehicles are eventually not affected (particularly in Brazil, where the energy matrix is largely dominated by hydroelectric 
power). We call these routes "permanent routes". Thus, if their operation is not interrupted, these routes shall not be part of the priority analysis.

199 The next step is to identify, in the OD survey dataset, the number of motorized trips associated with each OD pair and the availability of public transport for the connections between zones (the MSC). All zones connected by permanent routes are considered as served by public transport. For all other routes, the priority order is based on the PTD. The PTD of each route is the sum of the actual motorised trips between the OD pairs served by the route (as shown in the example of Tables 1 and 2). The route with the highest priority is the one with the maximum PTD value. The classification of the other routes in terms of priority takes into account the incremental PTD found in the OD pairs added by each route to the demand already served by the previously selected routes. This process of selection is done until all routes are ranked or no other route is able to add more PTD. When the additional PTD of a route is equal to zero, no more users will benefit from the inclusion of this route. Therefore, there is no justification for operating it during a crisis.

210 Table 3 contains the values of the PTD and the ranking list for the hypothetical example discussed in 211 Tables 1 and 2, which has no permanent routes. Route 1 has the highest total PTD. Therefore, it is 212 the first route to be selected. Route 3 is selected next in the list of priority and Route 2 is not selected, 213 because it adds no PTD to Routes 1 and 3 combined.

214 Table 3 Quantifying the Potential Transit Demand (PTD) for the example of Tables 1 and 2

\begin{tabular}{|c|c|c|c|c|c|}
\hline $\begin{array}{c}\text { Origin } \\
\text { zone }\end{array}$ & $\begin{array}{c}\text { Destination } \\
\text { zone }\end{array}$ & $\begin{array}{l}\text { Motorised } \\
\text { trips }\end{array}$ & Route 1 & Route 2 & Route 3 \\
\hline 1 & 2 & 79 & OD pair served & OD pair not served & OD pair served \\
\hline 1 & 5 & 54 & OD pair served & OD pair not served & OD pair not served \\
\hline 2 & 3 & 41 & OD pair not served & OD pair not served & OD pair served \\
\hline 4 & 5 & 32 & OD pair served & OD pair served & OD pair not served \\
\hline 5 & 2 & 35 & OD pair not served & OD pair not served & OD pair not served \\
\hline \multicolumn{3}{|c|}{ Potencial Transit Demand (PTD) } & $165(79+54+32)$ & 32 & $120(79+41)$ \\
\hline \multicolumn{3}{|c|}{ Priority } & 1 & - & - \\
\hline \multicolumn{3}{|c|}{ Incremental PTD } & - & 0 & 41 \\
\hline \multicolumn{3}{|c|}{ Priority } & 1 & - & 2 \\
\hline
\end{tabular}

216 The public transport (PT) scenarios considered in the analysis refer to the number of routes in 217 operation in that scenario. If public transport is completely unavailable (i.e., no routes are operated 218 and all trips have to be made by active modes), this is scenario PT0. If only one route, which is the 219 one classified with the highest priority (i.e., the maximum PTD), is selected, this is scenario PT1. The 220 subsequent public transport scenarios follow the same logic (PT2, PT3, etc.) until scenario PTm, in 221 which the last route $m$ adds PTD to the previously selected routes. When no permanent routes (i.e., 
routes not affected by the crisis) are considered, PT0 is exactly the case considered by Martins et al.

223 (2019) for setting up the scenarios of active modes. The PTD of each scenario is easily obtained by 224 the combination of the PTD matrices of all routes operating in that scenario.

\subsection{Combined scenarios and classification of trips}

The analysis of resilience conducted in this study uses a combination of active modes scenarios and public transport scenarios. The scenarios of active modes are formed by different combinations of MPD for walking and for cycling, whereas public transport scenarios are associated with the number of routes in operation, as described in session 3.3. Hence, the identification of the combined scenarios shows the MPD values for walking and cycling and the number of public transport routes selected. Scenario W0.5B1.5PT1, for example, is the case with a MPD of 0.5 kilometres for walking (W), a MPD of 1.5 kilometres for bicycling (B) and one public transport (PT) route in operation.

For each scenario, the OD survey trips are classified in resilience levels (based on Folke et al. (2010) and Martins et al. (2019)). Walking or cycling trips equal to or shorter than the respective MPD and public transport trips served by the routes in operation in the scenario under analysis are persistent trips. Active mode trips longer than the MPD are classified as exceptional trips. All motorized trips shorter than the MPD and car trips longer than the MPD but covered by the public transport routes in operation are considered adaptable trips. Finally, all motorised trips longer than the MPD and not covered by the transit routes in operation are the transformable/at risk trips, which are the trips most affected by the imposed constraint.

Persistent, adaptable and exceptional trips are resilient, whereas transformable trips are at risk because they are substantially more vulnerable than the other classes of trips. The overall resilience level of a city is given by the percentage of resilient trips in relation to total trips. According to Martins et al. (2019), overall resilience can be classified as follows: very low (0 to 20.0\%), low (20.1 to $40.0 \%$ ), medium (40.1 to $60.0 \%$ ), high (60.1 to $80.0 \%$ ), and very high (80.1 to $100.0 \%)$.

Even though the calculation method is not complex, it requires some time and effort to compute all PTD values for determining the priority routes. To increase the efficiency of the method, we implemented the algorithm described in sections 3.3 and 3.4 using Python.

\subsection{Classification, spatial distribution and socioeconomic characteristics of the trips}

After being classified as resilient (i.e., persistent, exceptional, or adaptable) or vulnerable (i.e., transformable/at risk), the OD trips can be mapped by their TAZ. The graphical outcomes can be used for identifying zones with high levels of vulnerability in each scenario. According to Cariolet et 
253 al. (2019), managers and decision-makers can use these maps to visualize critical regions of the city 254 for developing strategies for improving the resilience of mobility.

255 The results can also be used to look for possible relationships between the trip classification and 256 socioeconomic characteristics (income, for example) of the travellers. This analysis can indicate 257 population groups that are particularly vulnerable to the crisis.

\section{Results and Discussion}

\subsection{The case studies}

260 We applied the methodology to two case studies in Brazil, the cities of São Carlos, São Paulo, and 261 the Metropolitan Region of Maceió (MRM), the capital of the State of Alagoas. These regions were 262 chosen as demonstration cases with different characteristics of location (inland versus coastal), in 263 public transport system (only bus versus bus and Light Rail Train, LRT) and in spatial and 264 demographic characteristics.

265 The scenarios for Maximum Possible Distances (MPD) for both active modes are a selection from 266 the ones tested in Martins et al. (2019), now combined with the number of bus routes. The selection 267 includes the scenarios with MPD that characterise the curves (five for each case study) and a set of 268 other scenarios with equidistant MPD values between the latter.

269 Sao Carlos has a population of 246 thousand inhabitants (estimation for 2017, Instituto Brasileiro de 270 Geografia e Estatística, (2010)). The city has a significant concentration of skilled jobs in academia, 271 services and manufacturing. A summary of the OD data is available in Table 4 and a map of the traffic 272 analysis zones (TAZ) is depicted in Figure 2(a). The distribution of the population density is depicted 273 in Figure 2(b). The public transit network is only served by buses, with 54 routes in operation 274 (licensed by the Municipality of São Carlos), mainly with radial itineraries and only a few with 275 circular itineraries. Values of MPD for active modes for São Carlos reach a maximum of $4.0 \mathrm{~km}$ for 276 walking and $12.5 \mathrm{~km}$ for bicycle, which combined with the maximum number of 28 bus routes that 277 supplies all potential transit demand (PTD) accounts for 290 scenarios (from scenario 278 SC_W0.0B0.0PT0 to scenario SC_W4.0B12.5PT28).

279 Table 4 Summary of the OD surveys for São Carlos and the Metropolitan Region of Maceió (MRM) 


\begin{tabular}{|c|c|c|c|c|c|c|c|c|c|c|c|c|}
\hline \multirow[b]{2}{*}{ City } & \multirow[b]{2}{*}{$\begin{array}{c}\text { Number of } \\
\text { TAZ }\end{array}$} & \multirow[b]{2}{*}{$\begin{array}{l}\text { Year of } \\
\text { Survey }\end{array}$} & \multirow{2}{*}{$\begin{array}{l}\text { Maximum } \\
\text { Distance } \\
\text { between } \\
\text { TAZ }(\mathrm{km})\end{array}$} & \multicolumn{9}{|c|}{ Trips } \\
\hline & & & & Total & Walking & $\begin{array}{c}\text { Mode } \\
\text { Share }(\%)\end{array}$ & Bicycle & $\begin{array}{c}\text { Mode } \\
\text { Share (\%) }\end{array}$ & $\begin{array}{c}\text { Public } \\
\text { Transport }\end{array}$ & $\begin{array}{c}\text { Mode } \\
\text { Share (\%) }\end{array}$ & Car & $\begin{array}{c}\text { Mode } \\
\text { Share (\%) }\end{array}$ \\
\hline São Carlos & 41 & $2007 / 2008$ & 12.5 & 6821 & 2883 & 33.5 & 222 & 3.2 & 1445 & 21.2 & 2871 & 42.1 \\
\hline $\begin{array}{c}\text { Metropolitan } \\
\text { Region of } \\
\text { Maceió } \\
\text { (MRM) }\end{array}$ & 83 & 2014 & 29.5 & 6038 & 2080 & 34.5 & 277 & 4.6 & 1764 & 29.2 & 1917 & 31.8 \\
\hline
\end{tabular}

281 


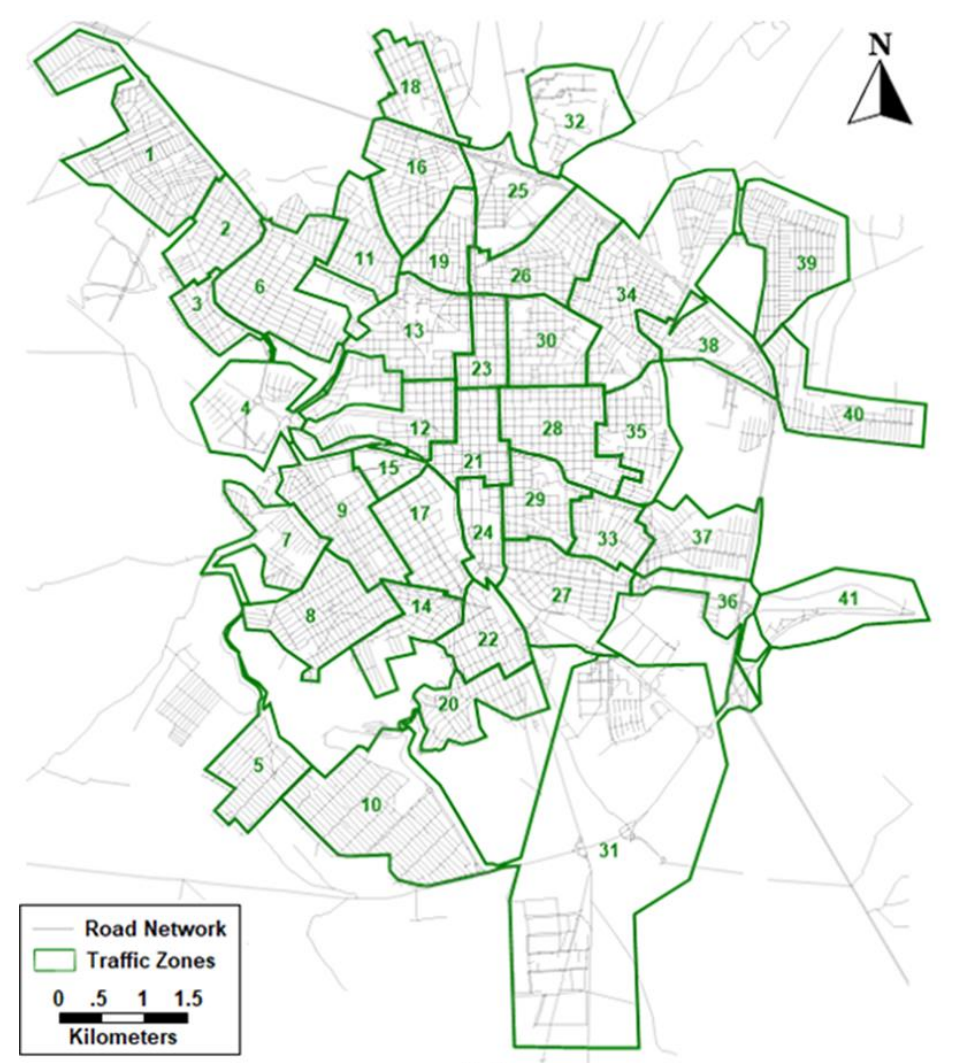

(a)

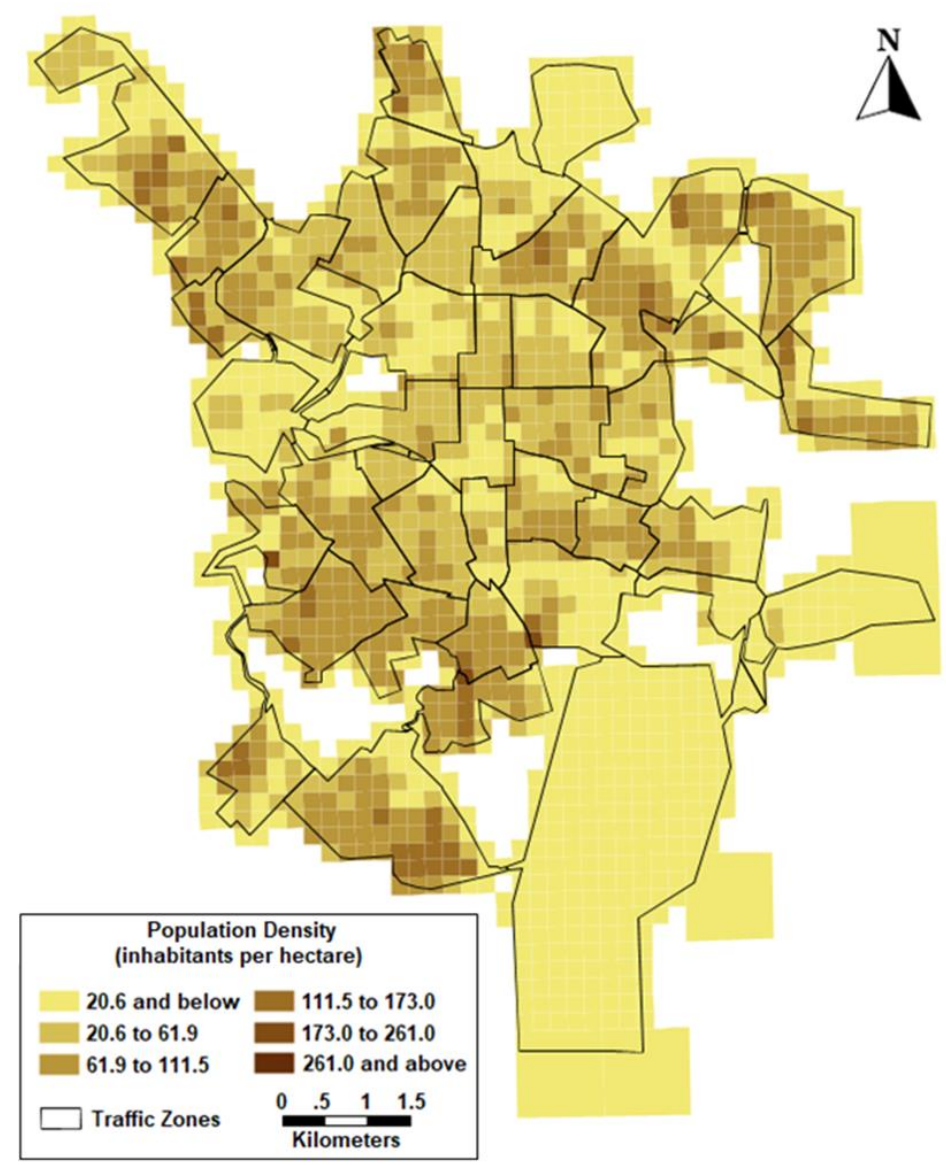

(b)

283 Figure 2 Maps of TAZ and population density for the city of São Carlos, SP 
284 Maceió has a population of 1.12 million inhabitants (estimation for 2017, Instituto Brasileiro de 285 Geografia e Estatística, (2010)). The metropolitan area includes the municipalities of Maceió, Rio 286 Largo and Satuba, and its economy is based on manufacturing and services with a strong influence 287 of several state and federal services. A summary of the OD data is available in Table 4 and a map of 288 the TAZ is depicted in Figure 3(a). The distribution of the population density is depicted in Figure 289 3(b). The public transit network has 96 bus routes in operation and one diesel-engined Light Rail 290 Train (LRT) route serving the three municipalities of Rio Largo, Satuba and Maceió. Values of MPD 291 for active modes for the MRM reaches a maximum of $4.0 \mathrm{~km}$ for walking and $27.5 \mathrm{~km}$ for bicycle, 292 which combined with the maximum number of 44 bus routes (that satisfy all PTD) results in 1170 293 scenarios (from scenario MRM_W0.0B0.0PT0 to MRM_W4.0B27.5PT44). 

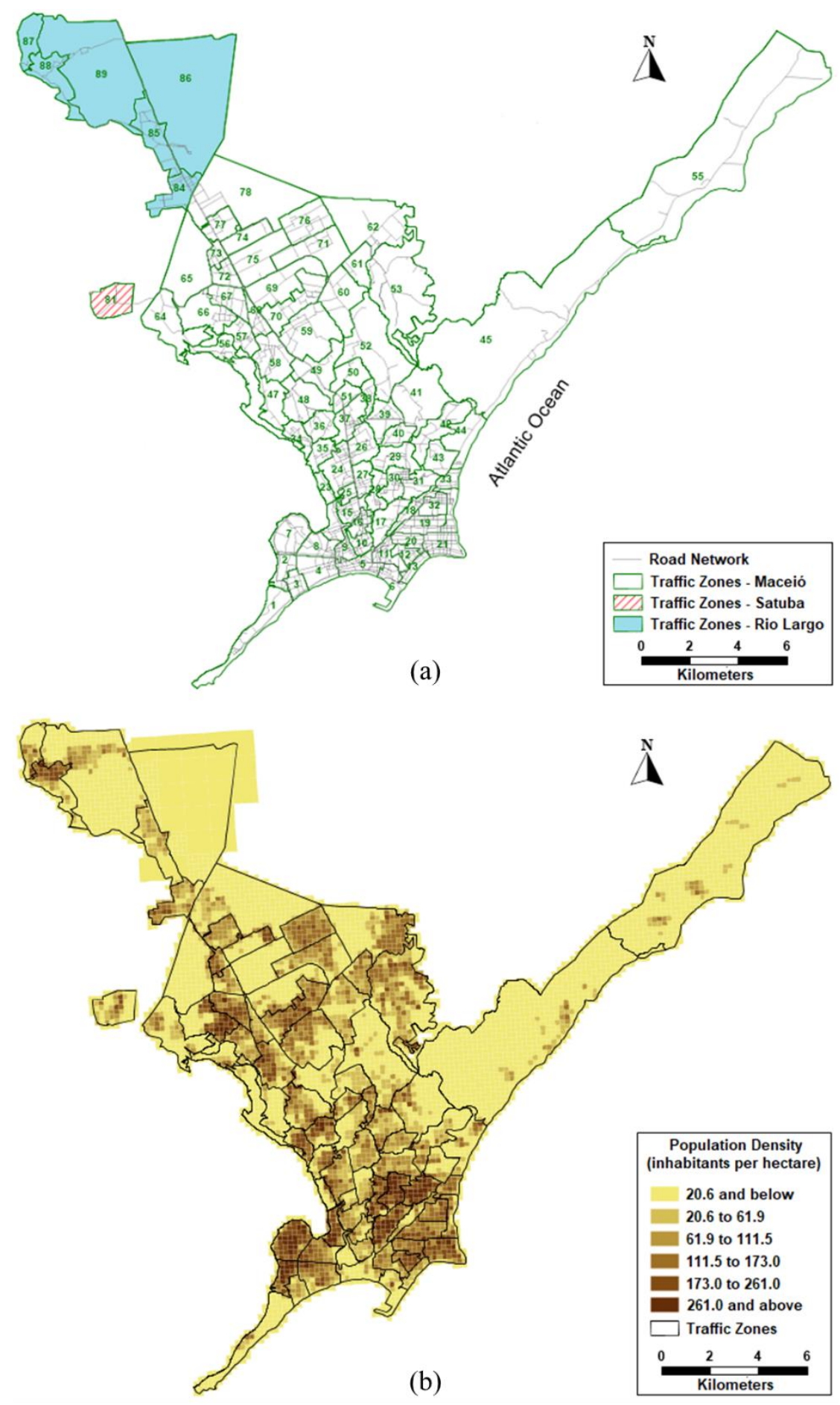

296 Figure 3 Maps of TAZ and population density for the Metropolitan Region of Maceió (MRM)

\subsection{Segmentation of trips and level of resilience}

298 The variations of the resilience levels are depicted in Figure 4 for São Carlos and in Figure 5 for the 299 MRM. In both graphics, each point of a given curve represents a scenario with a combination of a 300 MPD for walking (W) and bicycle (B) combined with a number of public transit (PT) routes that have 301 been considered not disrupted in the scenario, ranked by the higher PTD (the sum of OD trips served 
by any bus route). To ensure legibility of the graphics, we opted to represent one curve per scenario,

303 instead of the surface that represents the three parameters (W, B and PT). The horizontal axis 304 represent the MPD for bicycle. Again, to ensure legibility, we opted to represent only some of the 305 curves, up to the scenario where new bus routes would not add new PTD (28 for São Carlos and 44 306 for the MRM).

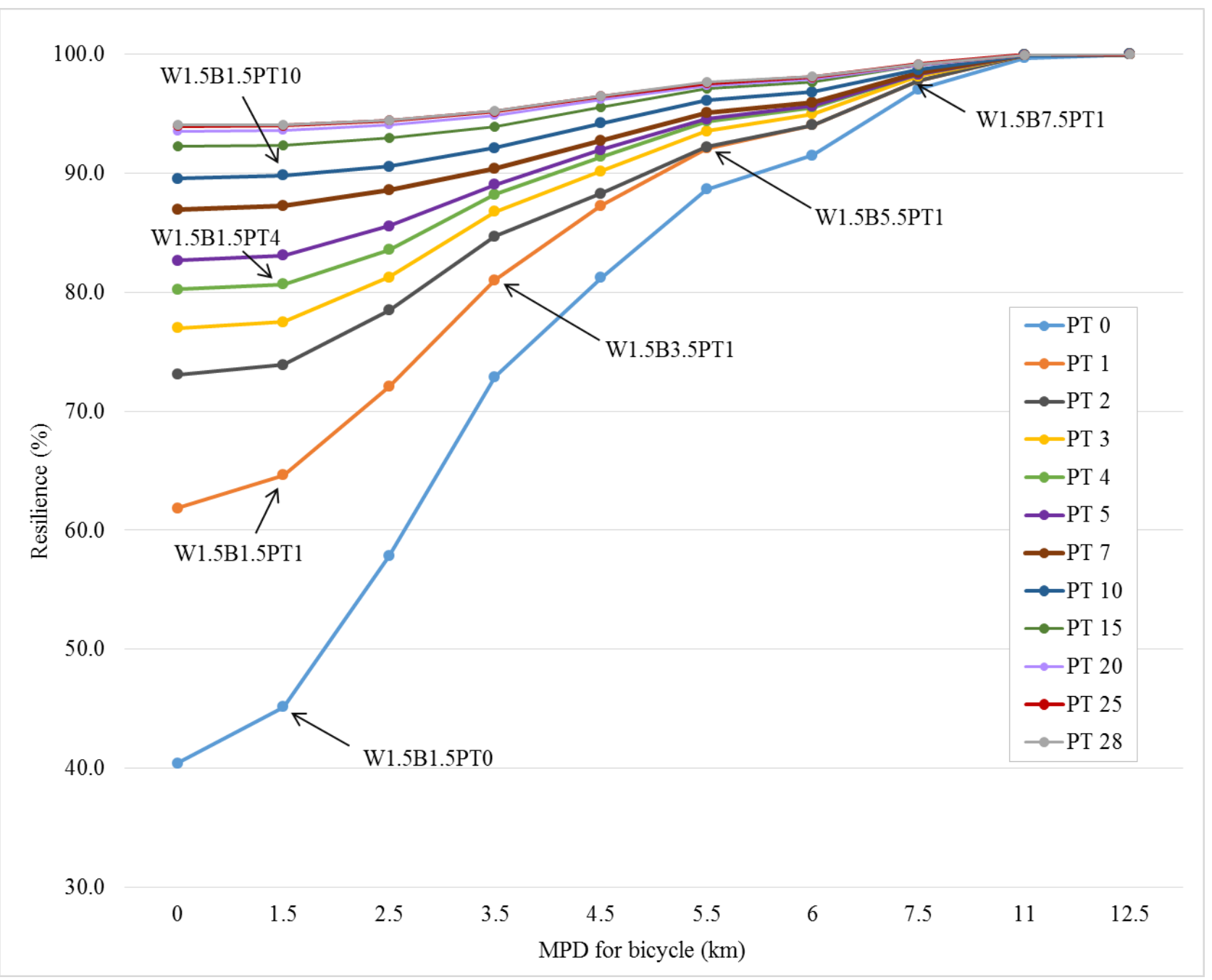

Figure 4 Variation of resilience levels for different MPD values for bicycle, considering multiple scenarios of PT for São Carlos, SP

310 São Carlos registers an entry level of $40.4 \%$ of resilience in the starting scenario SC_W0.0B0.0PT0,

311 where only intrazonal and exceptional trips are made on walking and cycling modes and no bus route 312 is in operation. When moving on to scenario SC_W0.0B0.0PT1 (one bus route in operation) there is 313 a jump to around $62 \%$ of resilience, as all trips between any given OD pair served by that bus route 314 can be made. When trips with longer MPD for bicycle are considered (MPD for walking is always 315 equal or smaller than the MPD for bicycle), jumps on resilience happen mainly because adaptable and persistent trips can then be made on walking and cycling modes. In these cases, gains given by 
317 the operation of more bus routes are smaller as the bus network increases its offer to more OD pairs.

318 All scenarios for São Carlos present a four stages behaviour, with inflection points with MPD at 1.5 $319 \mathrm{~km}$ when gains in resilience increase faster as more trips become persistent or adaptable, $3.5 \mathrm{~km}$ when 320 these gains start slowing down to a new slow growth stage at $7.5 \mathrm{~km}$, to finally disappear for trips 321 with MPD over $11 \mathrm{~km}$. This behaviour is consistent along all public transit scenarios, with decreasing 322 gains (but not constant in value) as all PTD for public transport is satisfied.

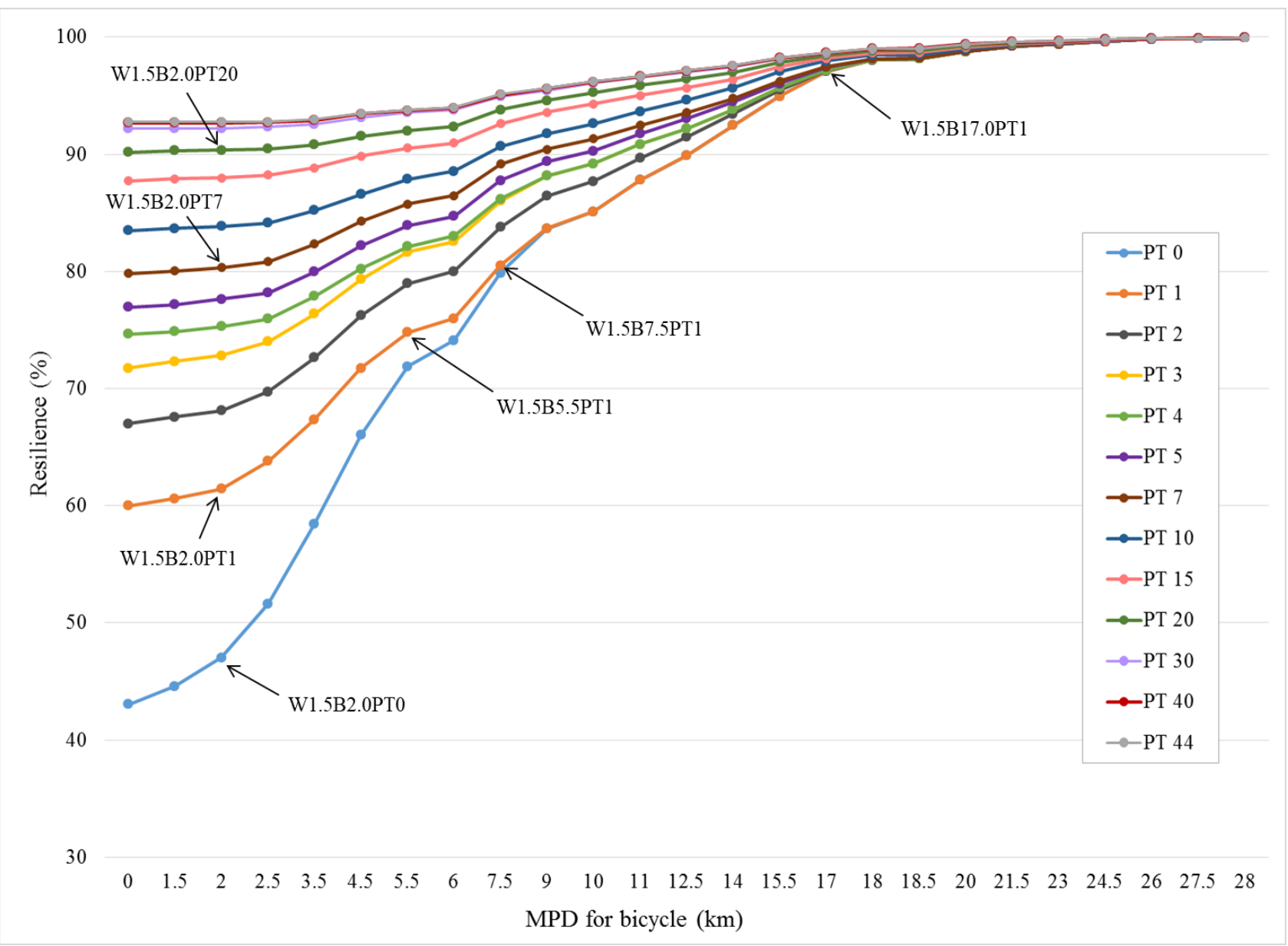

Figure 5 Variation of resilience levels for different MPD values for bicycle, considering multiple scenarios of PT for the Metropolitan Region of Maceió (MRM)

327 The MRM registers an entry level of $43.0 \%$ of resilience in the starting scenario 328 MRM_W0.0B0.0PT0. When moving on to scenario MRM_W0.0B0.0PT1 (one bus route in 329 operation) there is a jump to around $60 \%$ of resilience. When trips with longer MPD for bicycle are 330 considered (again, MPD for walking is always equal or smaller than the MPD for bicycle), jumps on resilience happen mainly because adaptable, persistent and exceptional trips can then be made on walking and bicycle modes. In these cases, and consistent with São Carlos, gains given by the 
333 operation of more bus routes are smaller as the bus network increases its offer to more OD pairs, 334 which in the case of MRM are larger due to the larger number of OD pairs. It is possible to observe 335 the same four stages behaviour for the MRM as for São Carlos. These have inflection points with 336 MPD at $2.0 \mathrm{~km}$ when gains in resilience increase faster as more trips become persistent or adaptable, $3375.5 \mathrm{~km}$ when these gains start slowing down at $7.5 \mathrm{~km}$ (interestingly the same value as for São Carlos), 338 to finally disappear for trips with MPD over $17 \mathrm{~km}$. This behaviour is once again consistent along all 339 public transit scenarios, with decreasing gains (again, not constant in value) as all PTD for public 340 transport is satisfied.

341 These behaviours for both São Carlos and the MRM present values of resilience just under $60 \%$ in 342 the case of scenarios with no public transport services and MPD for bicycle under around $2.5 \mathrm{~km}$ for 343 São Carlos and under around $3.5 \mathrm{~km}$ for the MRM. These values account for significant to high 344 resilience according to the classification presented in section 3.4.

345 One observed finding is that (without considering operational or network issues) a reduced number 346 of bus routes is necessary to be in operation to ensure higher levels of resilience. In the case of São 347 Carlos, only 28 bus routes (or $52 \%$ out of a total of 54 routes) are sufficient to ensure levels of 348 resilience of around $94 \%$ or above. For the MRM, the number of bus routes that satisfy all the PTD 349 is 44 , representing $45 \%$ out of the 97 routes (including the LRT). This could perhaps represent a better 350 distribution of the bus routes in the MRM than in São Carlos, but further research is needed to confirm 351 this assumption.

\section{$352 \quad 4.3$ Spatial distribution of trips per TAZ}

353 We present the spatial distribution of trips per TAZ classified by their resilience level to help localise 354 areas of potential increase of resilience with the maintenance of operating bus routes in case of 355 disruption. These maps show the variation of resilience in the inflexion points identified in the 356 previous section, illustrating the variation of the spatial distribution when the MPD for bicycle 357 increases to encompass trips done in the majority of the area of the city. Figure 6 depicts, for São 358 Carlos, the spatial distribution of trips in which, for a MPD for walking and bicycle of 1.5 kilometres, 359 the number of available bus routes increases. The impact of having one route in operation is 360 significant, adding much more resilience especially in the peripheral areas of the city, mainly in the 361 south, southwest and the northwest of São Carlos. Resilience gains starts to occur more in the city 362 centre and less in the peripheries once more routes become operational, a consequence of more public 363 transport offer. Figure 7 depicts the variation of resilience in São Carlos when one bus route is 364 available and the MPD for cycling increases. For scenarios with the same number of available bus 365 routes, more substantial gains happen in peripheral areas of the city for larger MPD; on the other 
366 hand, the city centre has more gains for shorter MPD because it already has a larger number of 367 resilient trips. The most peripheral areas in the southwest and northwest of the city gain much more 368 of having available bus routes than from increased MPD as they depend more on longer trips to access 369 jobs and services.
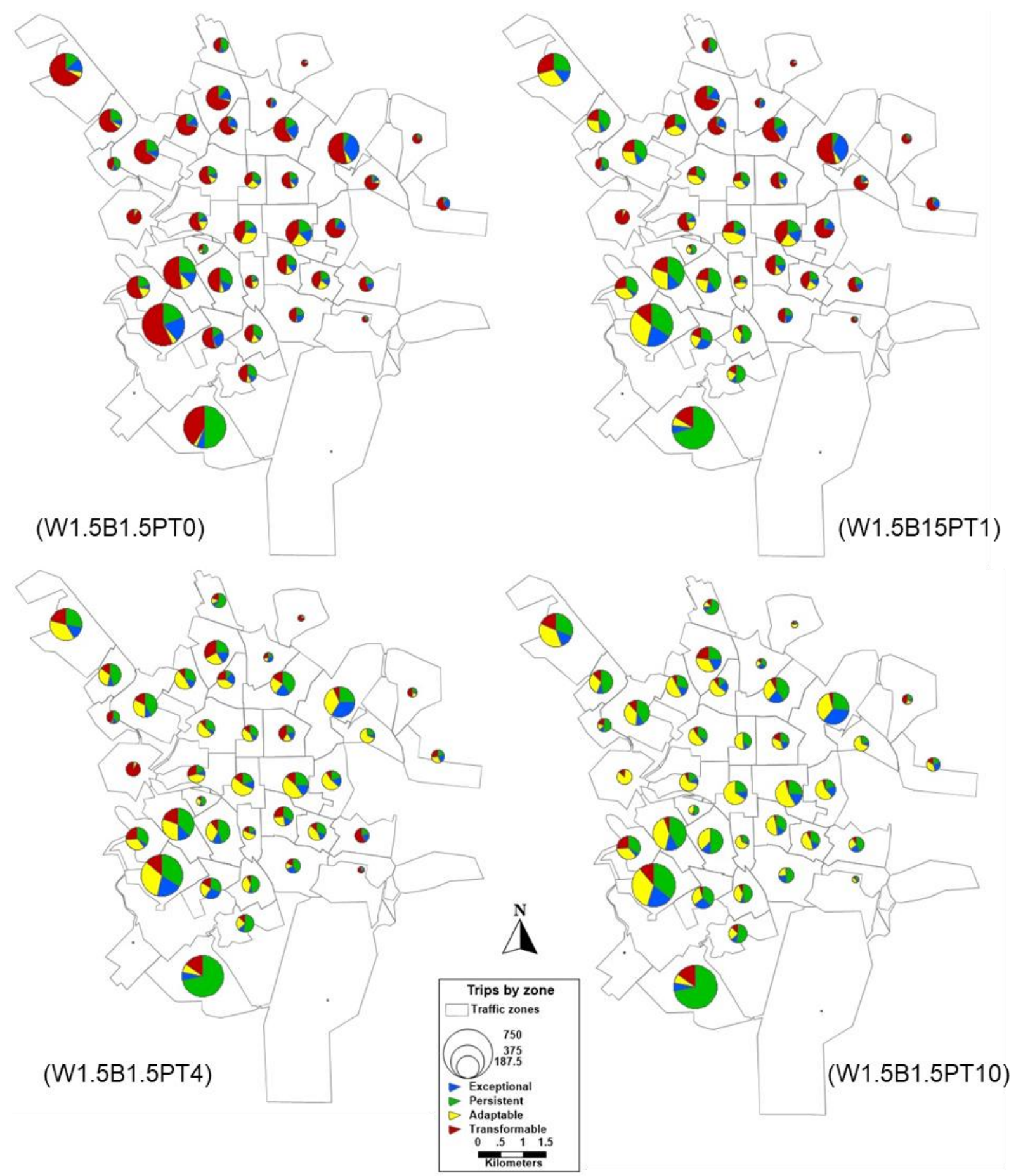

372 Figure 6 Spatial distribution of resilience per TAZ in São Carlos for a sample of scenarios with MPD for both walking and bicycle of 1.5 kilometres and different number of available bus routes 

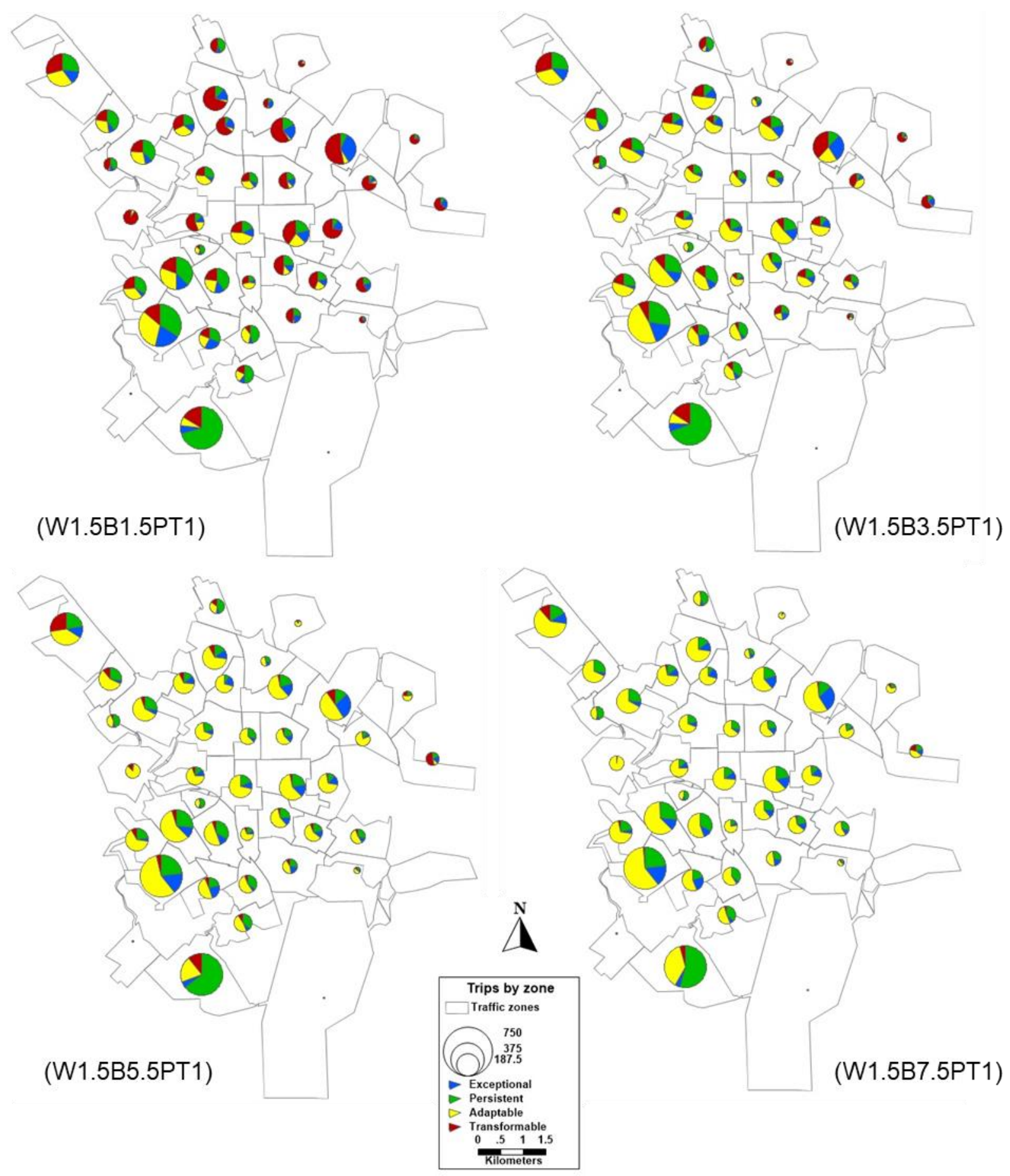

376 Figure 7 Spatial distribution of resilience per TAZ in São Carlos for a sample of scenarios with one available bus route and variable MPD for bicycle, MPD for walking of 1.5 kilometres

Figure 8 depicts, for the MRM, the spatial distribution of trips in which, for a MPD for walking of 1.5 kilometres and for bicycle of 2.0 kilometres, the number of available public transit routes increases. Gains in resilience depend on a large number of available routes (larger than in São Carlos). This is a consequence of the city scale and from a large concentration of jobs and services in the 
historic centre in the south (close to the ocean), whereas residential areas are more evenly spread 383 across the MRM. Figure 9 depicts, for the MRM, the variation of resilience when one public transit 384 route is available and the MPD for cycling increases. Resilience gains start to happen only for 385 relatively long bicycle MPD (above around 7.5 kilometres) which reflects the longer average trip 386 distance in this city, again a consequence of the displaced centrality of the MRM. The size of the 387 MRM and the consequent large average trip length creates a strong dependence of the public 388 transport. Therefore, the impact of adding routes is significantly higher than the impact of having larger MPD for cycling. This is visible by the variation of persistent trips across the MRM.

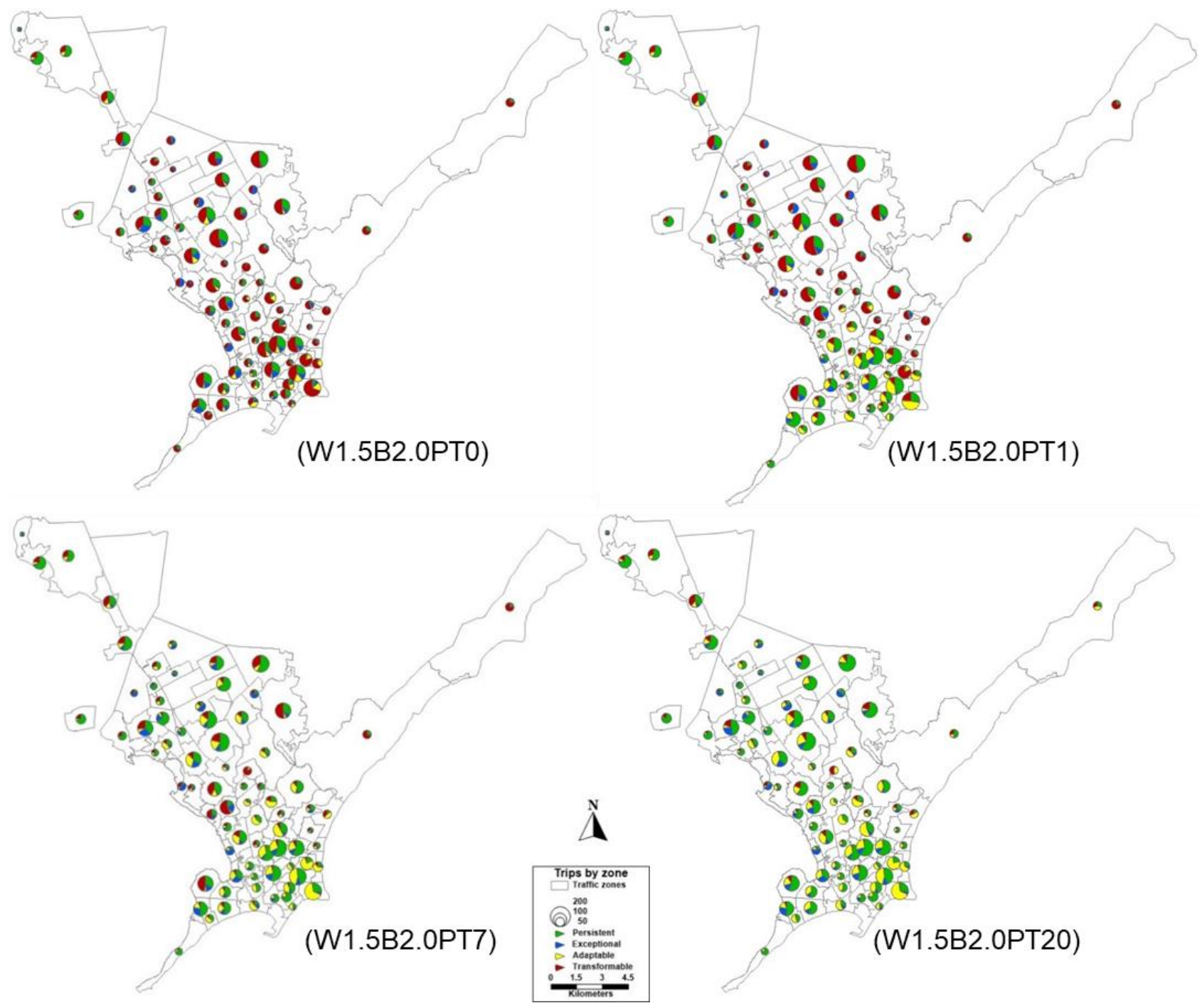

Figure 8 Spatial distribution of resilience per TAZ in the MRM for a sample of scenarios with MPD bicycle of 2.0 kilometres and different number of available public transport routes 


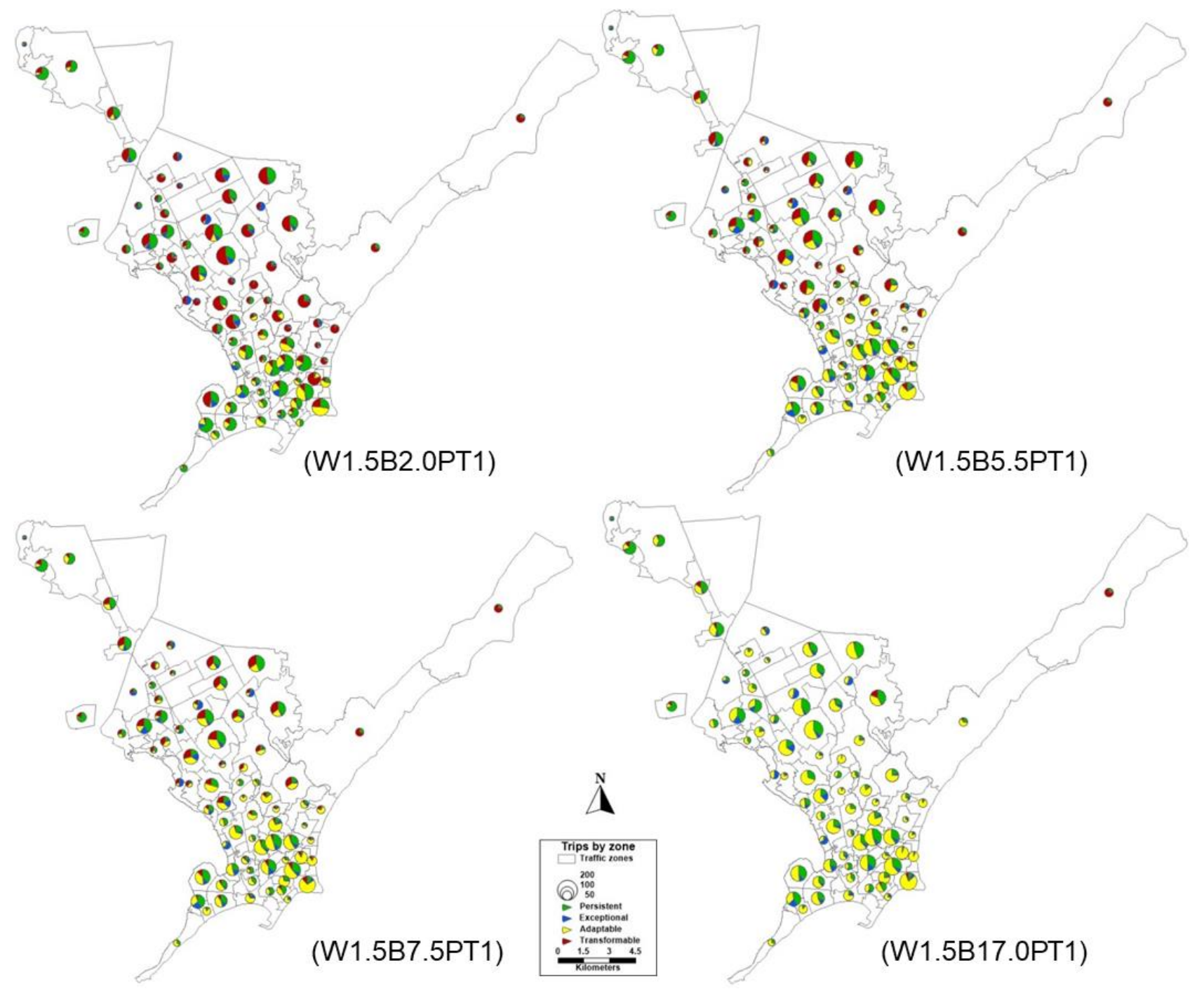

395 Figure 9 Spatial distribution of resilience per TAZ in the MRM for a sample of scenarios with one available public transport route and variable MPD for bicycle

\subsection{Resilience and income}

398 We used the scenarios mapped in the previous section to analyse the relationship between trip 399 distances and their resilience classification and individual income (for São Carlos in Figure 10) and 400 household income (for the MRM in Figure 11). This difference in the income variable shows 401 consistency between the two case studies as the average size of households in the MRM is 3.4, a value 402 calculated from the data of the OD survey.

403 A straightforward and generalised comparison between the two case studies is not feasible, as there 404 are variations among income classes or mobility scenarios within each case study and between the 405 two cities. However, results show interesting indications regarding particular aspects of income 406 distribution and urban mobility resilience, as discussed next. 
407 When considering the variation of MPD for cycling with a constant number of available public 408 transport routes (the right column of Figure 10 and Figure 11), it is interesting to see that patterns 409 follow the ones presented by Martins et al. (2019) in which public transport was considered as a 410 motorised vehicle. Transformable/at risk trips become adaptable for lower income levels in both São 411 Carlos and the MRM. Another interesting observation is that lower income levels have less gains in 412 resilience as less transformable/at risk trips become adaptable or persistent, more so in the MRM than 413 in São Carlos, as depicted in the left column of Figure 10 and Figure 11. Statistical tests did not 414 provide any relevant correlation between the observed values of trip distance and income and 415 resilience classes.

416 To analyse further the data, we plotted the distribution of trips per resilience class by brackets of 417 income, depicted in Figure 12 (for São Carlos) and Figure 13 (for the MRM). We classified all the 418 trips with a non-null response for income level into quartiles; we also created a classification for all 419 the trips with no income or no answer for income. We present, for each scenario, on the right the 420 distribution of absolute values of trips classified by resilience class within each income bracket. On 421 the left, we present the share of these classes for each income bracket. Data for São Carlos has a very 422 high value of responses with no income or no answer for income, which may be a consequence of the very large university student population in the city.

424 In both case studies, the higher the income bracket is the larger is the share of transformable/at risk 425 trips, more so when the MPD is constant and the number of public transport routes varies (the left 426 column of Figure 12 and Figure 13). This effect only disappears when many routes are in operation. 427 In the MRM, when increasing the number of available routes, more transformable/at risk trips become 428 persistent than adaptable, which reflects the local importance of public transport, as previously observed for the spatial distribution of trips in the MRM. When still looking at constant MPD and 431 the largest change from transformable/at risk to persistent occurs, especially in the MRM. The share 432 of transformable/at risk trips for the most optimistic scenarios (higher number of public transport 433 routes) is equalised across all income brackets for both cities. The same trend occurs in optimistic 434 scenarios with higher MPD when it varies for the same number or routes (the right column of both 435 Figures), but with larger changes for intermediate values of MPD (below 3.5 kilometres for São 436 Carlos and 5.5 kilometres for the MRM). For both case studies and for all scenarios, the share of 437 persistent trips increases as the income decreases whereas the share of adaptable trips decreases in 438 the same direction. 

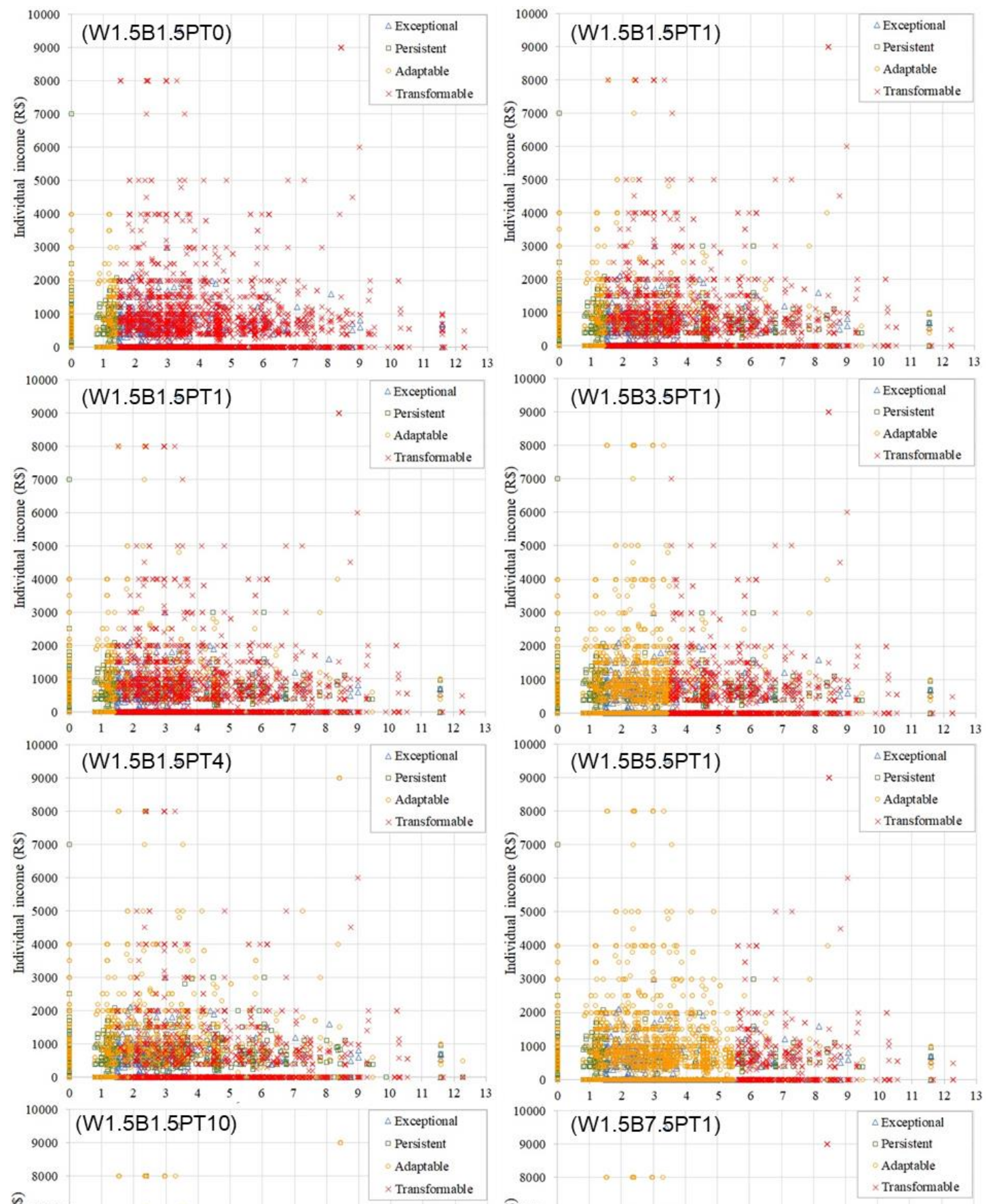

441 Figure 10 Relationship between distance of trip and average monthly individual income (in Brazilian 442 Reais, R\$) for São Carlos: (left) with MPD for bicycle of 1.5 kilometres as $n$ and different number of 443 available bus routes; (right) with one available bus route and variable MPD for bicycle 

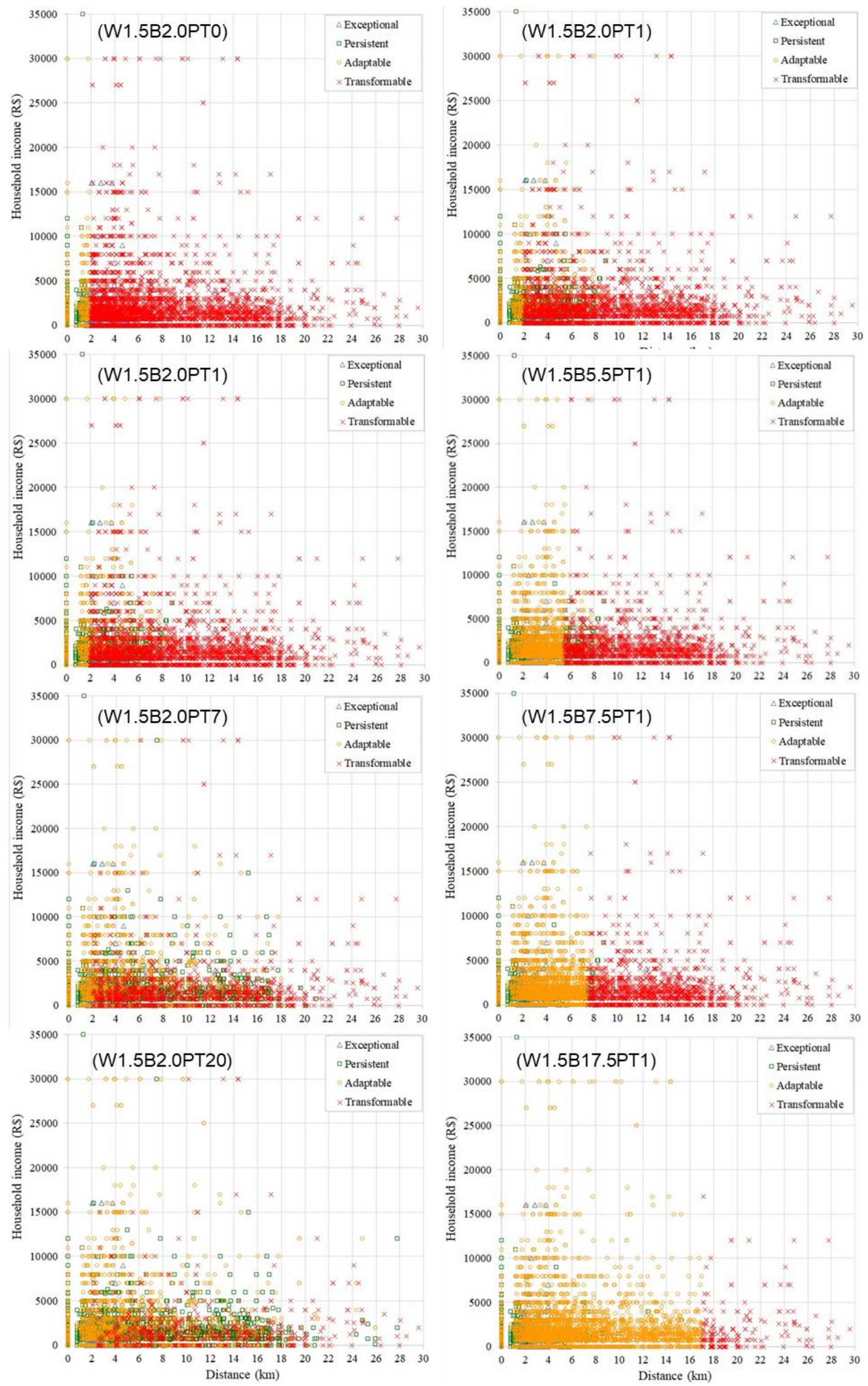

445 Figure 11 Relationship between distance of trip and average monthly household income (in Brazilian 446 Reais, R\$) for the MRM: (left) with MPD for bicycle of 1.5 kilometres and different number of 447 available bus routes; (right) with one available bus route and variable MPD for bicycle 


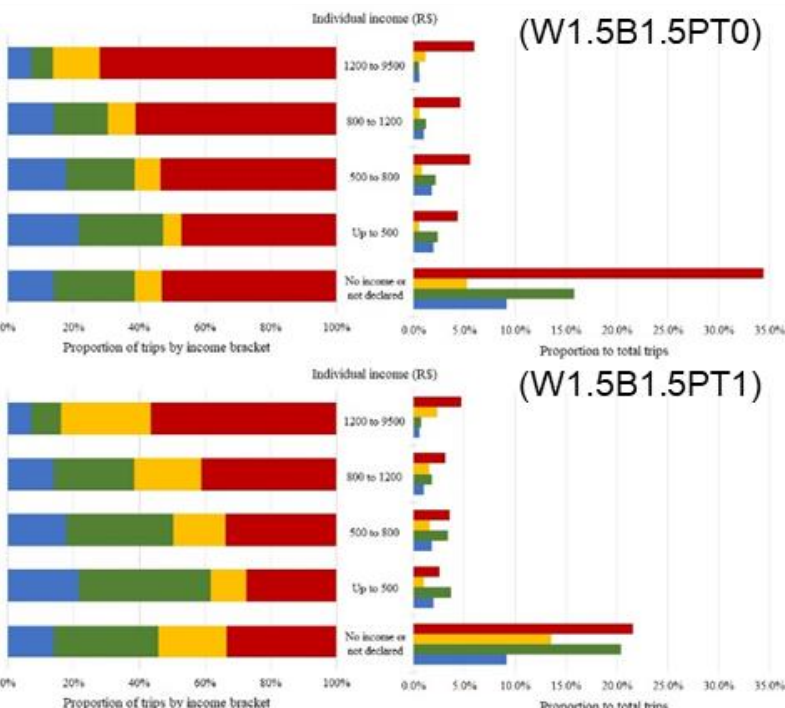

(W1.5B1.5PT4)

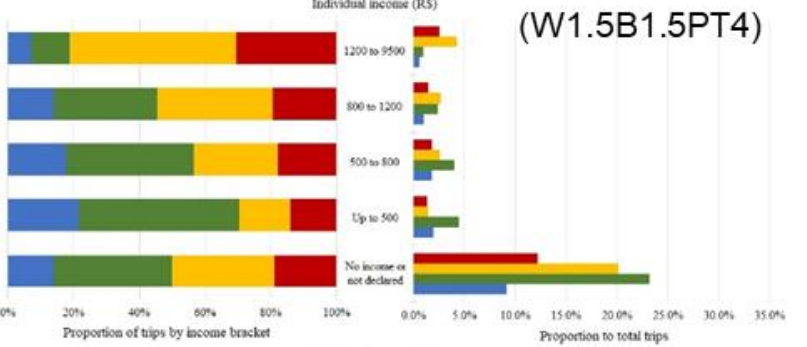

(W1.5B1.5PT10)

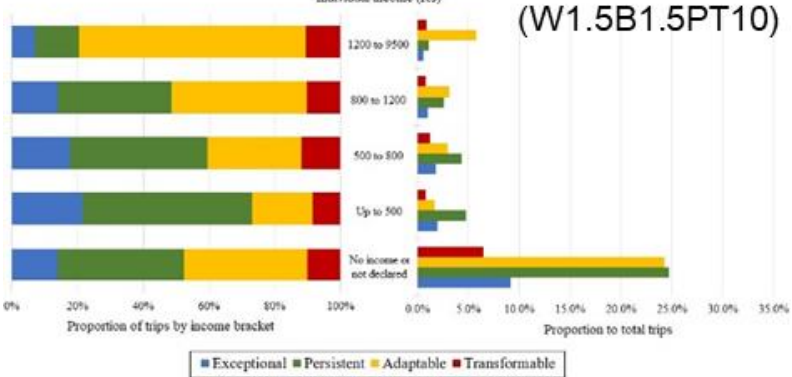

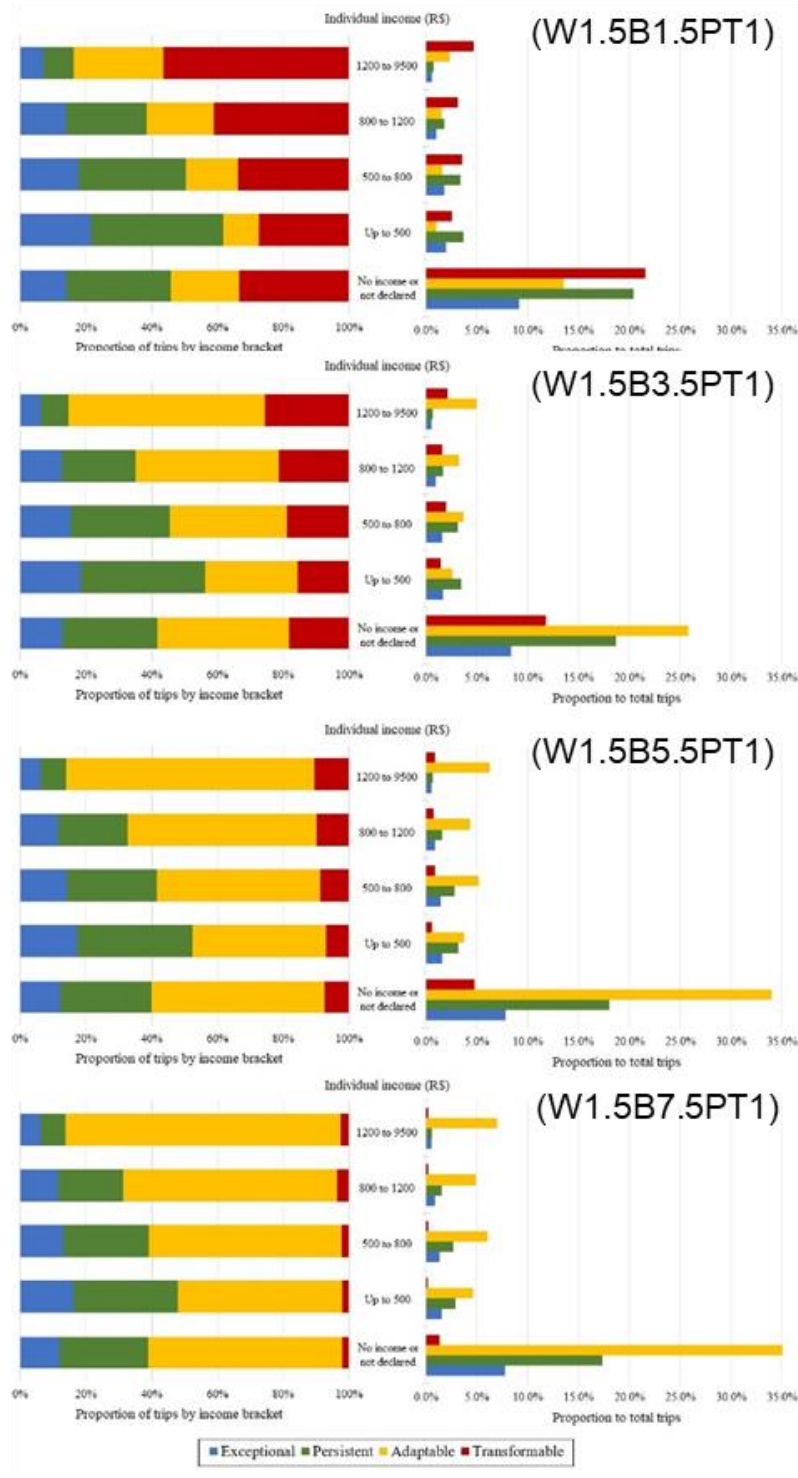

450 Figure 12 Sample of scenarios with the distribution of trips per individual income brackets for São 451 Carlos: (left) with MPD for bicycle of $1.5 \mathrm{~km}$ and different number of available bus routes; (right) 452 with one available bus route and variable MPD for bicycle 

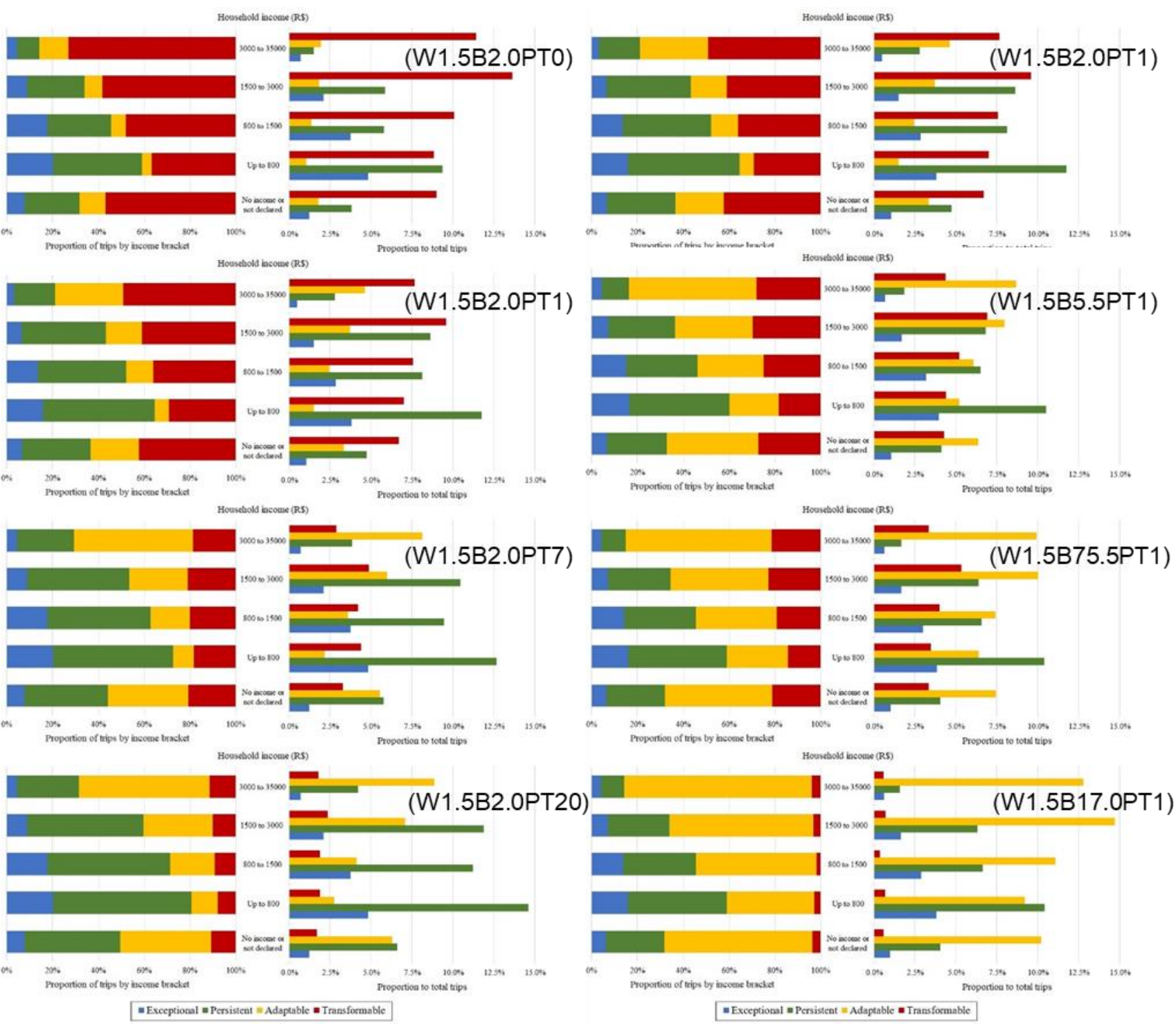

Figure 13 Sample of scenarios with the distribution of trips per individual income brackets for the 458 MRM: (left) with MPD for bicycle of $2.0 \mathrm{~km}$ and different number of available public transport 459 routes; (right) with one available bus route and variable MPD for bicycle

460 Conclusion

461 The paper presented the consideration of public transport in assessing an overall indicator of 462 resilience using the OD matrix for two case studies. This is a new iteration of the methodology 463 developed by Martins et al. (2019), as we now considered incremental scenarios in which public 464 transport routes would become operational in the event of disruption (when car trips would not be 465 possible). These scenarios are combinations of Maximum Possible Distances (MPD) for trips to be 466 made in active modes (walking and cycling) and the number of available public transport routes; the 467 latter were prioritised by their potential transit demand (PTD) measured in the OD pairs for public 
transport. The overall indicator of resilience is the share of trips that can be maintained on or transferred to active modes plus the share of trips can be maintained on or transferred to the operational public transport routes in each scenario. The method has been automated to allow the analysis of larger transit systems using GIS and Python tools.

The method was successfully applied to two cities in Brazil, São Carlos, SP, (290 scenarios) and the Metropolitan Region of Maceió, MRM, AL, (1170 scenarios) showing that the inclusion of more public transport routes adds resilience to the system. However, a higher number of public transport routes results in increasingly smaller resilience gains, showing that there is scope for strategic thinking when designing an operational response to a disruption. These gains are also more substantial for shorter MPD for walking and cycling, as the public transit routes will increase mobility options for longer distances. The spatial distribution of trips suggests an influence of centrality and of the location of the main centres of residences, jobs and services. A more compact city such as São Carlos has a more spatially even distribution of resilient trips, especially when the public transport is considered. A more sprawled city such as the MRM presents a more uneven distribution of resilience. The analysis of public transport resilience shows that small increments in the supply of public transport routes are key to ensure resilient trips to lower income classes, as higher levels of accessibility are maintained in the event of disruptions.

The incorporation of public transport in the methodology allowed a better characterisation of resilience, its spatial patterns and how resilience distribution relates to income. By incorporating the public transport, we have made the method more representative of the transport system. Results also show that there is a substantial gain of resilience once at least one public transport route is made available, with resilience gains decreasing in value as more routes become operational. This clearly suggests the potential of this method in supporting strategic planning of responses to disruption that might involve a phased redeployment of public transport services post-disruption. The resilience gains highlighted from our approach of prioritising the public transit routes can be used to test the impacts of different priority criteria (for example, minimum legal service during strikes, fuel costs per route or connectivity).

The proposed method also shows potential for transferability. The use of a commonly available mobility management tool, the OD matrix, combined with a detailed characterisation of the transport network (with distances measured over the road network) and the public transport routes makes the method easy to apply in both large and small urban areas as well as in more or less data rich contexts. The reliability of our resilience index comes from the robustness of OD matrixes, a validated mobility management tool used for decades in multiple different contexts. Our method does not require high technical expertise provided that an OD matrix is available, increasing the potential use of the 
resilience index by decision-makers in multiple contexts. However, some design assumptions limit the way the index represent the transport system. For example, we assumed some simplifications when considering TAZ and their centroids. When data is available, higher resolution methods could incorporate geographical coordinates of the relevant features (origin and destination of each trip or of transit stops), a study that remains a suggestion for further research.

Besides that, further avenues of this research will include an operational analysis of resilience, the consideration of resilience in trips to hierarchical networks of public facilities (e.g. hospitals and schools), the integration between transport lines, the impact of significant technological change towards electrical mobility and localised disruptions (in the whole system or per mode). Another research area will focus on the use of new mobility services (e.g. ridesourcing and sharing services) as operational tools to deal with disruption, based on decisions taken considering resilience levels in the system. Finally, there is scope to explore the potential of linking big data sources, as traffic sensors or mobile data, in analysing on-the-fly resilience levels.

\section{Acknowledgements}

This research was supported by São Paulo Research Foundation-FAPESP/The University of Manchester (Grant 2017/50309-9) and National Council for Scientific and Technological Development - CNPq (Grants 308436/2015-6 and 130795/2018-6).

\section{Reference List}

Berche, B., Von Ferber, C., Holovatch, T., Holovatch, Y., 2009. Resilience of public transport networks against attacks. Eur. Phys. J. B 71, 125-137. https://doi.org/10.1140/epjb/e200900291-3

Berdica, K., 2002. An introduction to road vulnerability: what has been done, is done and should be done. Transp. Policy 9, 117-127. https://doi.org/https://doi.org/10.1016/S0967070X(02)00011-2

Bruneau, M., Chang, S.E., Eguchi, R.T., Lee, G.C., O’Rourke, T.D., Reinhorn, A.M., Shinozuka, M., Tierney, K., Wallace, W.A., Von Winterfeldt, D., 2003. A Framework to Quantitatively Assess and Enhance the Seismic Resilience of Communities. Earthq. Spectra 19, 733-752. https://doi.org/10.1193/1.1623497

Cariolet, J.-M., Vuillet, M., Diab, Y., 2019. Mapping urban resilience to disasters - A review. Sustain. Cities Soc. 51, 101746. https://doi.org/10.1016/J.SCS.2019.101746

Chan, R., Schofer, J.L., 2016. Measuring Transportation System Resilience: Response of Rail Transit 
to Weather Disruptions. Nat. Hazards Rev. 17. https://doi.org/10.1061/(ASCE)NH.15276996.0000200

Coaffee, J., Therrien, M.C., Chelleri, L., Henstra, D., Aldrich, D.P., Mitchell, C.L., Tsenkova, S., Rigaud, É., 2018. Urban resilience implementation: A policy challenge and research agenda for the 21st century. J. Contingencies Cris. Manag. https://doi.org/10.1111/1468-5973.12233

Cox, A., Prager, F., Rose, A., 2011. Transportation security and the role of resilience: A foundation for operational metrics. Transp. Policy 18, 307-317. https://doi.org/10.1016/j.tranpol.2010.09.004

D'Lima, M., Medda, F., 2015. A new measure of resilience: An application to the London Underground. Transp. Res. Part A Policy Pract. 81, 35-46. https://doi.org/10.1016/j.tra.2015.05.017

Donovan, B., Work, D.B., 2017. Empirically quantifying city-scale transportation system resilience to extreme events. Transp. Res. Part C Emerg. Technol. 79. https://doi.org/10.1016/j.trc.2017.03.002

Duy, P.N., Chapman, L., Tight, M., 2019. Resilient transport systems to reduce urban vulnerability to floods in emerging-coastal cities: A case study of Ho Chi Minh City, Vietnam. Travel Behav. Soc. 15. https://doi.org/10.1016/j.tbs.2018.11.001

Fernandes, V.A., Rothfuss, R., Hochschild, V., Da Silva, M.A.V., Da Silva, W.R., Steiniger, S., Dos Santos, T.F., 2019. Urban resilience in the face of fossil fuel dependency: The case of Rio de Janeiro's urban mobility. Urbe 11. https://doi.org/10.1590/2175-3369.011.e20180160

Fernandes, V.A., Rothfuss, R., Hochschild, V., Da Silva, W.R., Santos, M.P. de S., 2017. Resiliência da mobilidade urbana: uma proposta conceitual e de sistematização. Transportes. https://doi.org/10.14295/transportes.v25i4.1079

Folke, C., Carpenter, S.R., Walker, B., Scheffer, M., Chapin, T., Rockström, J., 2010. Resilience thinking: Integrating resilience, adaptability and transformability. Ecol. Soc. 15. https://doi.org/10.5751/ES-03610-150420

Holling, C.S., 1996. Engineering Resilience versus Ecological Resilience. Eng. within Ecol. constraints 31-44. https://doi.org/10.17226/4919

Holling, C.S., 1973. Resilience and Stability +4050 of Ecological Systems. Annu. Rev. Ecol. Syst. $4,1-23$.

Hong, J., Tamakloe, R., Lee, S., Park, D., 2019. Exploring the topological characteristics of complex public transportation networks: Focus on variations in both single and integrated systems in the Seoul Metropolitan Area. Sustain. 11. https://doi.org/10.3390/su11195404

Jin, J.G., Tang, L.C., Sun, L., Lee, D.H., 2014. Enhancing metro network resilience via localized 
integration with bus services. Transp. Res. Part E Logist. Transp. Rev. 63, 17-30. https://doi.org/10.1016/j.tre.2014.01.002

Krumdieck, S., Page, S., Dantas, A., 2010. Urban form and long-term fuel supply decline: A method to investigate the peak oil risks to essential activities. Transp. Res. Part A Policy Pract. 44, 306322. https://doi.org/https://doi.org/10.1016/j.tra.2010.02.002

Leobons, C.M., Gouvêa Campos, V.B., Mello Bandeira, R.A. De, 2019. Assessing Urban Transportation Systems Resilience: A Proposal of Indicators. Transp. Res. Procedia 37, 322329. https://doi.org/10.1016/j.trpro.2018.12.199

Let's work together, 2020. Let's work together. Nat. Rev. Earth Environ. 1, 1. https://doi.org/10.1038/s43017-019-0017-2

Leung, A., Burke, M., Cui, J., 2017. The tale of two (very different) cities - Mapping the urban transport oil vulnerability of Brisbane and Hong Kong. Transp. Res. Part D Transp. Environ. https://doi.org/https://doi.org/10.1016/j.trd.2017.10.011

Linkov, I., Bridges, T., Creutzig, F., Decker, J., Fox-Lent, C., Kröger, W., Lambert, J.H., Levermann, A., Montreuil, B., Nathwani, J., Nyer, R., Renn, O., Scharte, B., Scheffler, A., Schreurs, M., Thiel-Clemen, T., 2014. Changing the resilience paradigm. Nat. Clim. Chang. https://doi.org/10.1038/nclimate2227

Lopes Da Silva, B., Érica, V., Santos, S., Beatryz, F., Tavares, R., 2019. Revista da Universidade Vale do Rio Verde | v. 17 | n. 1 | jan./jul 1.

Martins, M.C. da M., Rodrigues da Silva, A.N., Pinto, N., 2019. An indicator-based methodology for assessing resilience in urban mobility. Transp. Res. Part D Transp. Environ. 77, 352-363. https://doi.org/10.1016/j.trd.2019.01.004

Mattioli, G., Philips, I., Anable, J., Chatterton, T., 2019. Vulnerability to motor fuel price increases: Socio-spatial patterns in England. J. Transp. Geogr. 78, 98-114. https://doi.org/10.1016/J.JTRANGEO.2019.05.009

Mattsson, L.-G., Jenelius, E., 2015. Vulnerability and resilience of transport systems - A discussion of recent research. Transp. Res. Part A Policy Pract. 81, 16-34. https://doi.org/https://doi.org/10.1016/j.tra.2015.06.002

Reggiani, A., Nijkamp, P., Lanzi, D., 2015. Transport resilience and vulnerability: The role of connectivity. Transp. Res. Part A Policy Pract. 81, 4-15. https://doi.org/https://doi.org/10.1016/j.tra.2014.12.012

Ribeiro, P.J.G., Pena Jardim Gonçalves, L.A., 2019. Urban resilience: A conceptual framework. Sustain. Cities Soc. 50, 101625. https://doi.org/10.1016/J.SCS.2019.101625

Santos, T., Silva, M.A., Fernandes, V.A., Marsden, G., 2020. Resilience and Vulnerability of Public 

647. https://doi.org/10.3390/su12020647

603 Seeliger, L., Turok, I., 2013. Towards sustainable cities: Extending resilience with insights from vulnerability and transition theory. Sustain. 5, 2108-2128. https://doi.org/10.3390/su5052108

Ta, C., Goodchild, A.V., Pitera, K., 2009. Structuring a definition of resilience for the freight 606 transportation system. Transp. Res. Rec. 19-25. https://doi.org/10.3141/2097-03

607 United Nations, G.A., 2015. UN GA Resolution A/RES/70/1 Transforming our world: The 2030 agenda for sustainable development.

609 Walker, B., Holling, C.S., Carpenter, S.R., Kinzig, A., 2004. Resilience, adaptability and transformability in social-ecological systems. Ecol. Soc. https://doi.org/10.5751/ES-00650-

612 Wiersma, J., Bertolini, L., Straatemeier, T., 2017. Adapting spatial conditions to reduce car 613 dependency in mid-sized 'post growth' European city regions: The case of South Limburg, 614 Netherlands. Transp. Policy 55, 62-69. https://doi.org/10.1016/J.TRANPOL.2016.12.004 615 Zhao, P., 2010. Sustainable urban expansion and transportation in a growing megacity: Consequences of urban sprawl for mobility on the urban fringe of Beijing. Habitat Int. 34, 236-243. https://doi.org/10.1016/j.habitatint.2009.09.008 